\title{
Antje Gunsenheimer
}

\section{El redescubrimiento de la historia indígena mexicana en el siglo XIX ${ }^{*}$}

\section{Introducción}

El presente volumen tiene como objetivo discutir la función de las prácticas de edición y de producción de literatura con respecto al proyecto de invención de la nación (las naciones) en el siglo XIX en América Latina. Dentro de esta meta, mi contribución se dedica especialmente al empeño de los intelectuales mexicanos en redescubrir la historia indígena mexicana, distanciándose de las ideologías fijadas en la época colonial. Su propósito principal fue desarrollar una tradición propia que fuera capaz de crear su propia identidad reconstruyendo las civilizaciones prehispánicas mexicanas. Entre los intelectuales aún considerados pioneros en la elaboración de una imagen histórica de la nueva nación mexicana, como Manuel Orozco y Berra o Joaquín García Izcabalceta, figuraba el abogado José Fernando Ramírez (1804-1871), quien parecía más bien aburguesado y cuya labor presentaré en este trabajo.

Con su modo de trabajar objetivo, meticuloso y cuidadoso, se dedicó a las grandes obras históricas de su época. Se opuso claramente a la recuperación de una memoria histórica polémica e intensamente politizada, propuesta por Carlos María Bustamante (1774-1848). ${ }^{1}$ Por este motivo sirvió como ejemplo a historiadores posteriores como Alfredo Chavero y Francisco del Paso y Troncoso. En un principio describiré brevemente su carrera profesional y su modo de trabajar. Posteriormente, me centraré en su elección de temas y documentos históricos, así como en la influencia que tuvo en la imagen histórica del siglo XIX de la clase alta mexicana acerca de las civilizaciones

* Agradecimientos: Hay dos personas que han intervenido para que este trabajo pudiera realizarse: Christine Winter de Velarde y Karla Ramírez Rosas. Quisiera expresar mis agradecimientos sinceros por su valiosa aportación en la traducción del texto.

1 Véase al respecto el artículo de Monika Wehrheim. 
indígenas antes y durante la conquista española. Sin embargo, esta imagen estaría incompleta si la mirada se limitara únicamente a la discusión en el ámbito mexicano, ya que los intelectuales mexicanos mantenían un intenso intercambio con numerosos científicos europeos y norteamericanos y se influenciaban recíprocamente. Así que vale la pena explicar brevemente y con algunos ejemplos la investigación sucesiva de la historia indígena, para determinar estas importantes redes. Comenzaré con una breve explicación de la "historia" de la cual estamos hablando cuando en realidad se trata de la "historia mexicana indígena" $\mathrm{y}$, sobre todo, por qué habría de redescubrirse y bajo qué circunstancias sucedió.

\section{La "historia indígena mexicana" precolombina: autores, temas y funciones}

En el período precolombino no existía "una única" historia indígena mexicana, ya que el área que ocupa ahora México, en las vísperas de la conquista, fue habitada por numerosas civilizaciones indígenas con diferentes lenguas, modos de vivir y unidades socio-políticas. Estas civilizaciones en parte fijaron y transmitieron por escrito su propia historia mediante diversos sistemas de escritura. Sin embargo, la gran mayoría transmitió su historia en forma oral de generación a generación.

Algunas civilizaciones indígenas llamaron la atención de los españoles por su similitud en organización socio-política, arquitectura, urbanismo y sistemas de comunicación a las civilizaciones europeas. Estas fueron los Aztecas (México Central), los Mayas (Sur de México y península de Yucatán, Guatemala y Belice) y los Mixtecos (en el actual estado federal de Oaxaca). ${ }^{2}$ Todos ellos trabajaron con sistemas de escritura de imágenes o silábicos plasmados en los medios más diversos, como por ejemplo en cerámica, papel, monumentos de piedra, madera, huesos, etc.

Como resultado de la colonización española de civilizaciones indígenas surgieron cinco tipos diferentes de fuentes históricas. Ellas formaban posteriormente, en el siglo XIX, la base de las reconstrucciones y recuperaciones de una historia "nacional mexicana".

2 Además también el imperio de los Tarascos en el actual estado de Michoacán. 
(1) Para los conquistadores y colonialistas españoles, los códices producidos con fibras de corteza de árbol eran los más llamativos, ya que se asemejaban más a la idea europea de un libro. Los códices son tiras de papel de 15 a $20 \mathrm{~cm}$ de ancho y de varios metros de largo, que fueron plegadas después de haber sido pintadas y rotuladas (en forma de "leporello"). Al principio de la conquista, los textos jeroglíficos no fueron valorados como escritura ni como libros por los españoles. De este asunto José de Acosta nos informa en su obra Historia Natural y Moral de las Indias (1590):

[...] que las cosas que tenían figuras las ponían con sus propias imágenes, y para las cosas que no había imagen propia, tenían otros caracteres significativos de aquello, y con este modo figuraban cuanto querían; [...] Pero porque sus figuras y caracteres no eran tan suficientes como nuestra escritura y letras, por eso no podían concordar tan puntualmente en las palabras, sino solamente en lo sustancial de los conceptos (Acosta 1987: 400).

En su contenido, la mayoría de ellos trata de textos históricos, religiosos, astronómicos y cosmológicos, que explican importantes rituales en la religión de los Aztecas, Mixtecas o Mayas y su visión del cosmos y del mundo. Algunos ejemplos famosos son el Códice Borgia del área Azteca (Glass 1975a: 63 y más amplio: Díaz/Rodgers 1993; Seler 1963; Sisson 1983) y los Códices de Dresde, Madrid y París del área Maya (Glass 1975a: 76-78; Lacadena 1999: 237-256; más amplio: Love 1994; Thompson 1972; Vail/Aveni 2004).

Estos documentos fueron contemplados con mucha curiosidad. Los primeros hallazgos incluso fueron enviados a la corte real española como regalo. En las palabras de López de Gómara:

Pusieron también con estas cosas algunos libros de figuras por letras, que usan los mejicanos, cogidos como paños, escritos por todas partes. Unos eran de algodón y engrudo, y otros de hojas de metal, que sirven de papel, cosa muy digna de ver. Pero como no los entendieron, no los estimaron (1965, parte II: 82).

Sin embargo, muchos otros fueron destruidos durante la evangelización y se prohibió su reproducción para impedir la transmisión de las ideas religiosas indígenas, con lo cual se perdió, en cierto modo, el sistema de escritura y su interpretación. ${ }^{3}$

3 En el auto da fé del año 1562 en Maní, en la península de Yucatán, p.ej., se quemaron decenas de códices mayas por el orden del provincial Fray Diego de 
(2) Varios de los códices que cuentan con sistemas de escritura prehispánicos, conservados hasta hoy, fueron producidos por encargo de conquistadores y misioneros (1521-aprox. 1545) y por eso muestran una mirada hacia una época pasada. En muchos casos éstos son copias de manuscritos antiguos o documentos adicionales a manuscritos ya existentes. Estos códices se ocupan también de la religión y la historia. Además, también se tratan temas como las formas sociales, la economía y las estructuras militares. ${ }^{4} \mathrm{Su}$ característica más particular es que los textos españoles acompañan y explican la escritura hecha con imágenes aztecas. Un ejemplo famoso es el Códice Mendoza, llamado así en honor al primer virrey de la Nueva España, Antonio de Mendoza. ${ }^{5}$

(3) Sin embargo, es mucho más amplia la relación sobre la historia indígena redactada por los propios conquistadores, seguida por los informes de los funcionarios y misioneros españoles. Estos textos comienzan a producirse aproximadamente a partir de 1550 y tratan de la historia de la civilización indígena, por lo cual también se incorporó el saber de diversos pueblos indígenas transmitido oralmente en la historiografía. ${ }^{6}$

(4) Mediante la introducción de instituciones educativas españolas, a partir de aproximadamente 1560 ó 1570, algunos representantes de la nobleza indígena elaboraron trabajos históricos. Ellos se apoyaban, al igual que los primeros misioneros y funcionarios españoles, en la interpretación de los códices y del saber transmitido oralmente, en la mayoría de los casos de su propia familia. Entre éstos, los trabajos más famosos son los de Hernando de Alvarado Tezozomoc, descendiente de la dinastía de Tenochtitlan, Domingo de San Anton

Landa (véase Clendinnen 1987: 72-92; Landa 1995). Más tarde, Sánchez de Aguilar describe que la posesión de un códice jeroglífico fue castigado (1987: 90).

4 Véase para más información Robertson (1994).

5 Véase en las referencias bibliográficas al fin del texto, Codex Mendoza (1992).

6 Para más información: Handbook of Middle American Indians, Vol. 12 y 13. Uno de los representantes más célebres es fray Bernardino de Sahagún. Entre 1550 y 1580 Sahagún llevó a cabo entrevistas a indígenas y se hacía explicar sus códices, para redactar finalmente una obra de trece tomos sobre la historia y civilización del México antiguo, en lengua castellana y azteca, conocida bajo los títulos de Historia General de las Cosas de Nueva España (texto castellano) y Codex Florentinus (texto en lengua nahua con numerosas ilustraciones). 
Muñón Chimalpahin Quauhtlehuanitzin, de la dinastía de Chalco, y Fernando de Alva Ixtlilxochitl, descendiente de la dinastía de Texcoco. Ellos escribieron tanto en lengua azteca como en lengua española. $^{7}$

(5) Se puede hablar de un quinto grupo: unos historiadores, en su mayoría frailes, que escribieron sobre la historia del imperio Azteca durante los siglos XVII y XVIII basados en obras escritas al principio de la época virreinal (fuentes secundarias como la obra de Francisco Javier Clavijero, 1731-1787; véase Ronan 1973: 276-297).

Los primeros cuatro tipos de fuentes tienen en común el hecho de que fueron escritos durante los primeros años de la colonización y de la evangelización por representantes indígenas, o bien, en estrecha colaboración con ellos. La mayoría de las obras se basó en manuscritos pictográficos prehispánicos que hoy en día en su mayoría ya no están conservados. Esto significa que la historia prehispánica de civilizaciones indígenas en forma escrita existe sólo en la reproducción de textos españoles, o bien, en textos de autores indígenas ya influenciados por la civilización y religión española. La mayoría del abundante corpus de escritura indígena ha desaparecido y los pocos códices preservados son difíciles de comprender porque el entendimiento interpretativo de la escritura no ha sido transmitido, o por lo menos no suficientemente (Anders/Jansen 1988: 18-37). A estos cinco tipos de documentos se referían los intelectuales del siglo XIX para hacerse un propio acceso histórico a la imagen prehispánica de México. Aunque ellos estaban bien conscientes de las perspectivas visuales españolas en los documentos, se dieron cuenta de que sin las descripciones españolas de la época colonial no podían interpretar los códices originales. Sin embargo, estas escrituras tenían que ser redescubiertas y recuperadas con mucho esfuerzo. Este proceso tuvo su origen en intereses muy variados.

\section{Las circunstancias del redescubrimiento de las historias indígenas en el siglo XIX}

Todos los tipos de documentos mencionados revelaron ciertas intenciones de los autores, o de sus patrones, y cumplieron estas intencio-

7 Véase los títulos individuales en las referencias bibliográficas. 
nes inmediatamente en el período de su producción. De esta manera, las amplias presentaciones socio-históricas de los misioneros sirvieron para informar a sus superiores y a los frailes en España que se preparaban para su actividad misionera en la Nueva España, así como para la búsqueda de estrategias misioneras adecuadas. En especial, los historiadores indígenas usaron sus trabajos para defenderse ante el tribunal en conflictos ocasionados por herencias, o bien, por conflictos relacionados a sus derechos de posesión de tierras ante la corona española. De este modo, después de haber sido utilizados, los trabajos desaparecieron en los diversos archivos clericales, coloniales o privados y cayeron en el olvido hasta finales del siglo XVIII. Además, se puede constatar que después de haberse establecido el virreinato en la primera mitad del siglo XVII, el interés inicial por la investigación de civilizaciones indígenas casi se había apagado. ${ }^{8}$ Por esta razón se puede hablar del redescubrimiento de la historia indígena. En primer lugar, es factible que una posible causa desencadenante de este redescubrimiento ocurrió en la época de la Independencia con la búsqueda inherente de ideales políticos comunes que se pensaba encontrar en la historia prehispánica. Finalmente, en las primeras dos décadas del período de la Independencia, se fundó el Museo Nacional de México con el objetivo de crear una imagen de la historia y el futuro de la nueva nación. La tarea fue contribuir a la nueva imagen con la historia de las culturas precolombinas.

Sin embargo, esta consideración sólo toma en cuenta un período muy corto. Cabe mencionar que el interés por la historia empezó más temprano y no se puede contemplar separadamente de los desarrollos en Europa. Con ello me refiero a la época de la Ilustración que abrió otro tipo de entendimiento de las ciencias naturales y humanas y de

8 Algunos trabajos clave proceden del siglo XVII y XVIII. En la mayoría de los casos se trata de reconstrucciones de la historia hechas por los misioneros de las diferentes órdenes en Nueva España. Con esta finalidad emplearon fuentes primarias de los años iniciales (como por ejemplo Diego López Cogolludo y su obra Tres Siglos de la Dominación Española en Yucatán o sea Historia de esta Provincia [1656]). Numerosas fuentes de la primera fase de contacto solamente se conocen mediante estos trabajos secundarios. Al mismo tiempo que se realizaban estas recuperaciones secundarias se desarrollaba un animado comercio de manuscritos originados en la época colonial temprana y manuscritos antiguos. Los representantes más famosos fueron el político Carlos Sigüenza y Góngora y el bibliotecario Lorenzo Boturini Benaduci (véase Glass 1975b: 473). 
sus campos de investigación (Stagl 2006: 41-43). Los viajes de exploración se convirtieron en viajes de investigación, si se piensa en los viajes de James Cook y de los investigadores que lo acompañaron en los años setenta del siglo XVIII. La exploración científica de varios territorios sacó a la luz testimonios históricos. De modo que el desarrollo cultural de civilizaciones humanas se convirtió en una cuestión de investigación clave ante la diversidad cultural universal cada vez más evidente (Peoples/Bailey 2006: 65-66). En este contexto se debe también considerar la decisión de la corona española del año 1786. El rey Carlos III, quien estaba interesado en las ciencias y los estudios históricos, dio la orden de hacer examinar las ruinas de $\mathrm{Pa}-$ lenque (en el estado actual de Chiapas en el sur de México), conocidas desde hace varias generaciones, por una tropa de soldados bajo la dirección del capitán de artillería Antonio del Río en 1786.

El informe de Antonio del Río se entregó a Madrid en 1787 junto con los dibujos de los edificios hechos por Ricardo Almendáriz y algunos fragmentos de piedra esculpidos con inscripciones jeroglíficas. Desde el punto de vista de los observadores de aquellos tiempos, tales ruinas nunca pudieron ser construidas, debido a su belleza arquitectónica y sus habilidades en el trabajo de relieves esculpidos, por los descendientes de la población indígena que parecía bastante atrasada. En base a estas conclusiones se buscaron informes de la época colonial temprana para resolver el origen de las ruinas y sus civilizaciones extintas (Coe 1992: 73-74; Eggebrecht 2000: 400-410) y para descifrar sus sistemas de escritura.

Por otro lado, no sólo los españoles, que actuaban por orden de la corona, sino también investigadores europeos participaron en la búsqueda de los misteriosos orígenes (Coe 1992: 74). Cuando se publicaron catorce manuscritos pictográficos, la investigación obtuvo un gran empuje. Entre estas publicaciones destaca la edición de "Vue des Cordillères" (1810) de Alexander von Humboldt porque contenía entre otros dibujos algunas páginas del Códice Maya de Dresde.

Según John B. Glass (1975a: 21), Humboldt con su afición por coleccionar, su discusión racional de los manuscritos y su renombre internacional como letrado contribuyó mucho a despertar el interés por la exploración de las culturas mexicanas. En 1824 continuó la exposición de 17 manuscritos de origen mexicano en Londres. No debe sorprender que solamente dos años antes, en 1822, una versión 
inglesa del manuscrito inédito de Antonio del Río sobre el descubrimiento de las ruinas de Palenque, fue publicada en Londres bajo el título Description of the Ruins of an Ancient City Discovered Near Palenque, in the Kingdom of Guatemala, in Spanish America. Apareció con los dibujos de Almendáriz, mostrando varios ejemplos de inscripciones jeroglíficas. Las importantes publicaciones de las "Antiquities of Mexico" (1831-1848) por Edward King, Viscount Kingsborough, se basaron en esto. Él gastó su patrimonio en hacer producir copias de los 16 códices que corresponden al original. Todo esto sucedió paralelamente al desciframiento de la escritura jeroglífica egipcia durante los primeros 25 años del siglo XIX. ${ }^{9}$ Este paralelismo seguramente no es una casualidad, sino que demuestra el creciente interés que iba despertándose en aquellos tiempos por las antigüedades y su exploración.

La investigación fue apoyada por la creación simultánea de archivos. En 1780 el rey español Carlos III le encargó al cronista Juan Bautista Muñoz documentar la historia española, con el fin de responder a las observaciones críticas a la monarquía española procedentes sobre todo de Inglaterra y Francia, según Charles Gibson (1973: 5). Muñoz recolectó para ello las copias de documentos originales que abarcaban 126 folios y logró, en este contexto, la instalación del Archivo General de las Indias en Sevilla en el año 1785 bajo la corona española. Además, Muñoz fue apoyado en su labor por funcionarios de la corona en ultramar, quienes compilaban textos coloniales para él y los dejaban copiar. Bajo el protectorado del virrey Conde de Revillagigedo II fue producida la Colección de Memorias de Nueva España abarcando 32 tomos de manuscritos. Dos copias fueron enviadas a España en 1792, mientras que una copia permaneció en México. Esta colección de documentos, que consiste en mapas de la época colonial temprana, informes geográficos, historia colonial y

9 Ya los sabios de la época del Renacimiento se ocupaban con la inscripción egipcia. Sin embargo, sólo la campaña militar de Napoleón a Egipcia, que fue acompañada por una numerosa cantidad de científicos, resultó en un interés nuevo. Junto con el descubrimiento de la Estela de Rosetta y los primeros resultados por Johan David Åkerblad en 1802 y Thomas Young en 1814, Jean-François Champolion tuvo el gran éxito en 1822 en el desciframiento (véase a este respeto Ray 2007). 
algunas antigüedades que no estaban especificadas, o sea códices prehispánicos, formó la base de una primera colección sistemática.

Su constante ampliación conllevó a que en 1832, durante la era de la Independencia, se fundara el Archivo General de la Nación (Gibson 1973: 5-6). Como consecuencia de la recuperación continua y de la catalogación de los materiales, numerosos documentos de la época colonial temprana se percibieron otra vez conscientemente. Además, los responsables del archivo tenían la orden de editar los documentos y de ponerlos a disposición de un círculo de usuarios más grande.

La lista de las obras publicadas impacta por su abundancia. Entre ellas se pueden mencionar las obras de autores coloniales españoles e indígenas, así como los numerosos trabajos individuales de renombrados historiadores mexicanos del siglo XIX respecto a descubrimientos arqueológicos, sistemas calendáricos de los pueblos Mayas, Aztecas y Tarascos (Cline 1973: 403-422).

Aquí se manifiesta que en este momento de investigación histórica se había descubierto una enorme cantidad de datos que fue absorbida con mucha impaciencia. Los temas de publicación parecen, a primera vista, poco enfocados cuando se habla del labrado de la piedra de sol azteca y enseguida de una contribución al calendario tarasco o bien de un juego misionero del siglo XVI en lengua azteca. Sin embargo, los temas de trabajo no estaban compilados al azar, sino más bien ponen de manifiesto la búsqueda de los historiadores de información explotable y continua.

Cabe mencionar que para comprender los códices aztecas no solamente tenían que dominar la lengua azteca, sino también tener una idea de los temas tratados en ellos. Por esta razón -como aún hoy en día es usual- se ha tratado de usar los informes y las descripciones procedentes de la época colonial temprana acerca de las antiguas culturas indígenas para comprender los temas y la sistemática de los códices mediante estos datos. Esto significaba que la búsqueda de escrituras correspondientes se dedicaba a un tema concreto, por ejemplo, sobre el calendario. Año tras año la búsqueda de documentos finalmente se convirtió en una verdadera afición de algunos intelectuales en el siglo XIX. Los viajeros de investigación europeos se estaban moviendo en este campo al igual que intelectuales mexicanos, empezando por Alexander von Humboldt, pasando por los norteamericanos Stephen Catherwood y William Hickling Prescott, el obispo de 
Yucatán Crescencio Carrillo y Ancona y muchos más. Así, el director de la Comisión Científica Francesa, Victor Duruy, describe en los primeros años de los sesenta del siglo XIX su esperanza de que uno de ellos quizás descubra uno de los pocos códices mexicanos o yucatecos que se han salvado de la destrucción (Keen 1991: 436). Efectivamente, esto sucedió después, ya que el abad Charles Étienne Brasseur de Bourbourg, quien lo acompañó en el viaje, descubrió en la sierra guatemalteca una copia del Popol Vuh, uno de los pocos testimonios de la cultura híbrida colonial que consiste en elementos mitológicos de la civilización prehispánica quiché maya y en ideas religiosas cristiano-europeas de la época colonial (Tedlock 1996: 21-60).

\section{Un protagonista del redescubrimiento: José Fernando Ramírez (1804-1871)}

Los protagonistas del redescubrimiento de los códices y tratados históricos fueron un grupo de intelectuales de origen europeo, norteamericano y mexicano que se conocían y se influenciaban mutuamente a través de sus trabajos, y que en parte también competían por las mismas posiciones profesionales. Anteriormente ya fueron mencionados brevemente Carlos María Bustamente (1774-1848), Manuel Orozco y Berra (1810-1881), Joaquín García Icazbalceta (1825-1894), Alfredo Chavero (1841-1906) y Francisco del Paso y Troncoso (1842-1916). Todos ellos prestaron grandes servicios a la publicación y recuperación del legado historiográfico y crearon las bases para el estudio de la lengua, escritura, calendario e historia de civilizaciones indígenas.

\subsection{Breve biografia}

Uno de los protagonistas del redescubrimiento es sin lugar a duda José Fernando Ramírez (1804-1871) quien fue designado por su alumno y sucesor Alfredo Chavero, en 1887, como "el primero de nuestros historiadores". Con esta afirmación no solamente enfatizó la labor de Ramírez, sino que al mismo tiempo hizo una nítida separación entre la investigación histórica formal, presentada por Ramírez, y los polémicos estrategas políticos como Carlos María Bustamante o también el elocuente Vicente Riva Palacio.

Ramírez nació en 1804 en Hidalgo de Parral, Chihuahua, de origen burgués. De joven estudió derecho y en 1832 abrió un bufete de 
abogados en Durango. Tres años más tarde obtuvo el cargo de Secretario del estado de Durango. Desde entonces ascendió continuamente en la jerarquía administrativa de los cargos estatales y temporalmente fue Senador de la República (1845-1847). Junto a sus actividades profesionales se dedicó a los estudios de actas históricas. Con este trasfondo y en relación a sus aptitudes jurídicas y administrativas es posible entender que en 1852 fue designado director del Museo Nacional. Esta posición la desempeñó sólo hasta 1854. Sin embargo, durante este corto período organizó el museo imponiendo un orden estructurado, y éste se conservó durante muchos años. Debido a las condiciones políticamente inestables y los grupos de poder cambiantes en México, decidió exiliarse en Europa en 1855. Por esta razón, vendió su abundante colección de manuscritos compilada hasta entonces, así como parte de su propiedad de tierras y de minas, y pasó junto con su familia dos años en Europa. Aprovechó su exilio para visitar numerosos archivos, como por ejemplo el de la Bibliothèque Nationale de París, con la finalidad de continuar sus estudios de la historia de México con los materiales de estos archivos. También en 1855 en Potsdam visitó a Alexander von Humboldt, a quien admiraba como investigador ejemplar y con el cual se sentía unido en el empeño por una ciencia histórica exacta.

De regreso en México, y una vez que las fuerzas políticas se constituyeron nuevamente, fue de nuevo designado director del Museo Nacional. Desempeñó este cargo hasta 1864. Como político más bien conservador, Ramírez mantuvo buenas relaciones con las respectivas redes políticas y económicas en México. Estas redes apoyaron al archiduque austríaco Maximiliano en su toma del poder y la creación de un imperio mexicano. A través de estas conexiones, Ramírez consiguió el cargo imperial de Ministro de Relaciones Exteriores. Después del triunfo sobre las tropas austríaco-francesas y el fusilamiento de Maximiliano, Ramírez se decidió una vez más por el exilio. De nuevo vendió sus propiedades y pasó sus últimos años de vida junto con su hija, su yerno y nietos en Bonn donde falleció en $1871^{10}$ (Cline 1973: 374-375, De la Torre Villar 2001, I: 73-93).

10 La familia vivió en el centro de Bonn en la Kaiserstraße. José Fernando Ramírez primero fue enterrado en el Cementerio Antiguo de Bonn. Algunos años más tarde, la familia decidió a volver a México y se llevó los restos mortales para enterrarlos en México. 


\subsection{Trabajos editoriales e históricos}

Apasionado por la historia de México, como muchos de sus contemporáneos, Alamán, Bustamante, Lafragua, Chavero, Icazbalceta, Orozco y Berra, pensó, ante la carencia de una historia que reflejara la doble vertiente que nos constituye: la hispánica-europea-occidentalista, y la indígena, de tan amplios cuanto diferentes alcances, en la elaboración de una historia de la nación que con tantos esfuerzos iniciaba su vida independiente. Para escribirla, era necesario contar con las fuentes que proporcionaran la información auténtica, reunirlas, pues se encontraban en la mayor dispersión y olvido, copiarlas y someterlas a rigurosa crítica, difundirlas y utilizarlas para permitir a los estudiosos penetrar en los arcanos pasados (De la Torre Villar 2001, I: 73).

Con estas palabras De la Torre Villar empieza la descripción de las obras editoriales e históricas de Ramírez. En resumen, al lector le saltan a la vista cuatro puntos claves:

(1) Los textos tratan de un gran número de observaciones históricojurídicas de pleitos, lo que tiene que ver simplemente con el hecho de que Ramírez durante toda la vida no había puesto fin a su actividad como abogado ni había perdido su interés en documentos jurídicos.

(2) Gracias a su trabajo de varios años en los archivos, Ramírez dispuso de una excelente visión general de los principales y extensos trabajos históricos de la historia mexicana prehispánica. Esto fue el resultado de sus numerosos estudios bibliográficos. Debido a ello, las obras finalmente editadas por él no son hallazgos aleatorios sino el resultado de una cuidadosa elección. A ellos pertenece la edición de la Historia de la Nueva España e Islas de la Tierra Firme de Fray Diego Durán, terminada aproximadamente en 1581, y editada por Ramírez en 1867. En su período de creación, esta obra se consideró como una de las primeras sinopsis que tomaba en cuenta numerosas fuentes indígenas de índole oral y escrita, contrario a los informes de los conquistadores Hernán Cortés o Bernal Díaz del Castillo, o bien de sus informantes como Francisco López de Gómara. Además, la Historia fue contemporánea a los trabajos de Fray Bernardino de Sahagún y Fray Toribio Motolinia, por cuyas ediciones de obras Ramírez también contrajo méritos. Los preparativos de edición para los manuscritos de Hernando Alvarado de Tezozomoc, Fernando de Alva Ixtlilxochitl y el Códice Tovar (más tarde denominado según su 
descubridor Códice Ramírez) que, aunque no se acabaron en su tiempo, muestran la incorporación de la perspectiva histórica indígena en el sentido de una tradición histórica europeo-indígena común descrita por De la Torre Villar:

Ramírez como buena parte de los historiadores del siglo XIX, no escapó al reclamo de la historia prehispánica. Puesto que trataban de formar al país, de dotarle de clara y completa conciencia histórica, tuvieron que aceptar y fortalecer la doble raigambre de nuestra procedencia. Siguiendo los lineamientos trazados por Eguiara y Eguren y Clavijero, atendieron tanto la ascendencia hispánica como la indígena (De la Torre Villar 2001, I: 80).

(3) Estas raíces europeo-indígenas de la nación mexicana, aún joven en aquellos tiempos, se nos manifiestan hoy en día de manera particular en los dos únicos trabajos históricos de Ramírez (además de apuntes y breves anotaciones en los trabajos de edición). El primero es un estudio biográfico sobre el conquistador y acompañante de Cortés, Pedro de Alvarado, con el título Proceso de residencia contra Pedro de Alvarado, ilustrado con estampas sacadas de los antiguos códices mexicanos, y notas y noticias biográficas, críticas, y arqueológicas ... paleografiado del manuscrito original el Lic. Ignacio L. Rayón, 1847. Como manifiesta el título del trabajo, éste resultó del interés en pleitos históricos, interés ya mencionado anteriormente. El segundo manuscrito sobre el tema "El bautismo de Motecuhzoma II, noveno rey de México", publicado por primera vez en $1863,{ }^{11}$ es singular porque entre el gran número de posibles temas históricos y sus escritores no se menciona el bautismo cristiano del soberano azteca Moctezuma por los testigos oculares Hernán Cortés y Bernal Díaz de Castillo. A fin de cuentas, es disputable si este bautismo realmente tuvo lugar. ${ }^{12}$ Justamente allí se basa el interés de Ramírez en un reprocesamiento, ya que su trabajo biográfico respecto a Moctezuma II puede ser aplicado a un estudio anterior de Bustamante que fue publicado en

11 Publicado en el Boletín de la Sociedad Mexicana de Geografia y Estadística, Tomo 10, pp. 357-381.

12 Sin embargo, Fray Toribio de Benavente Motolinia (también editado por Ramírez) informa sobre el bautismo de un hijo de Moctezuma, aproximadamente quince años después de la conquista (véase Historia de los Indios de la Nueva España, Tratado II, Cap. 3, p. 84 en la edición de Edmundo O'Gorman del año 1995). 
1829 bajo el título Historia del Emperador Moctheuzoma Xocoyotzin.

(4) Como cuarto y finalmente último aspecto, respecto al trabajo de edición de José Fernando Ramírez, es muy notable que en la revisión de textos históricos buscara una clara corrección y complementación con los trabajos precedentes de Carlos María Bustamante (1774-1848). Por ejemplo, esto se muestra en la nueva edición de la Crónica Mexicana de Hernando de Alvarado Tezozomoc, que ya había sido publicada en 1822 por Bustamante con muchas faltas, o bien con interpretaciones de los textos controvertidas. A este mismo grupo pertenece también la nueva edición de la obra de Bernardino de Sahagún que igualmente ya había sido publicada por Bustamante en 1820-1830 en doce tomos. En la versión de Bustamante, al igual que en los textos de Sahagún editados por Kingsborough (1830-1831), Ramírez identificó numerosas faltas y errores de modo que, desde su punto de vista, no fue posible una reproducción histórica adecuada. Sin embargo, estas correcciones se efectuaron en una edición póstuma (Cline 1973: 376-377, 404-406).

\subsection{El contexto internacional y nacional de la historiografía}

Tal como ya mencioné anteriormente, no se pueden considerar los trabajos editoriales y el reprocesamiento de fuentes antiguas de Ramírez y sus contemporáneos mexicanos reduciéndose únicamente al discurso dentro de México. Los historiadores mexicanos del siglo XIX mantuvieron contactos continuos con historiadores norteamericanos y europeos, con los cuales compitieron, por cierto, pero al mismo tiempo también les unieron largas amistades académicas, y se nutrieron mutuamente a través de su trabajo. Un fuerte impulso y chispa a la vez representaron los trabajos del norteamericano William Hickling Prescott, quien en la primera mitad del siglo XIX presentó dos extensos trabajos respecto a la conquista del Perú y a la conquista de México. De esta manera competitiva, los historiadores mexicanos fueron invitados a crear sus propias obras y Ramírez aceptó esa invitación. Allí puede haber estado la inspiración para el trabajo histórico de Ramírez, quien en un principio sólo se dedicaba a actas jurídicas. En respuesta a la publicación de la History of the Conquest of Mexico 
(1836) de Prescott, Ramírez escribió un tratado de varias páginas sobre las rectificaciones necesarias en la obra. Grandeza y lealtad frente al objeto de investigación se muestran en la reacción de Prescott que integró las anotaciones de Ramírez en la traducción española de 1844 y con esto le concedió a Ramírez la primera palabra en el discurso histórico nacional del siglo XIX (Prescott 1844). De ahí en adelante, les unió un intercambio académico fructífero, que no finalizó a pesar de una competencia temporal por ciertas posiciones (ambos compitieron por ejemplo por el cargo de director del museo).

Del mismo modo, los esfuerzos alemanes por una historiografía nacional fueron influyentes. Por ejemplo, Ramírez mantuvo contactos con historiadores alemanes antes de sus estadías de exiliado y observó la formación de la Monumenta Germaniae Historica. Este compendio de numerosos volúmenes se considera hasta hoy en día como prototipo de una documentación moderna con -por la primera vezreglas editoriales. En 1819, el político prusiano Heinrich Friedrich Karl Reichsfreiherr vom und zum Stein fue creador de una colección histórica extensa de crónicas, textos legales, cartas, escritos y documentos que debió poner en relación el movimiento nacional alemán del siglo XIX con raíces medievales. ${ }^{13}$ De este modo, casi todas las fuentes medievales fueron editadas con un aparato de anotaciones crítico y moderno y fueron puestas a disposición de un gran círculo de lectores. Este ejemplo sirvió de modelo para muchos historiadores de otros países (Gibson 1973: 4) y podemos reconocer su efecto directo en los trabajos de Ramírez.

Aunque José Fernando Ramírez no presentó una obra histórica tan extensa como la de sus contemporáneos como el ya mencionado William Hickling Prescott o el alemán Leopold von Ranke que también fue persona influyente para Ramírez, se convirtió en ejemplo para generaciones sucesivas de historiadores mexicanos. Fue honrado merecidamente por el establecimiento de un aparato o un módulo exacto y crítico de analizar fuentes de las épocas precolombinas e hispánicas. Se dice que su meta máxima fue la elaboración de una historia nacional, una historia independiente, constituyéndose de sus raíces hispánicas-europeas-occidentalistas e indígenas. Así, Howard F. Cline concluye que

13 Véase: <www.mgh.de/dmgh/>, página de la red de la compañía actual. 
[...], Ramírez makes a major advance over many of the same activities undertaken earlier by Bustamante. Ramírez was aware of many of the native pictorial and prose sources, as well as those in the European traditions related to ethnohistory, most of which he had examined in the original, and many of which he had copied. His own studies, whole now generally superseded, lack the polemical tone of Bustamante, and his publications of texts are generally reliable. With contemporaries like Joaquín García Icazbalceta, with whom he corresponded, Ramírez was influential in improving and extending the national scholarly tradition in Mexico of gathering and publishing for scholarly use the basic native pictorial and written records from which reliable ethnohistory could be written (Cline 1973: 377).

\section{La historiografía y su influencia en la representación de la nación en el espacio público}

¿Cómo se puede medir la contribución de los historiadores del siglo XIX a la formación de la nación mexicana y a la conciencia histórica de sus ciudadanos? Es cierto que José Fernando Ramírez así como sus predecesores y sucesores se caracterizaron por una intensa actividad de publicación. Y ya que se trataba de largas presentaciones históricas o de reflexiones individuales de trabajos, en su mayoría sólo estaban accesibles a un pequeño círculo de simpatizantes en lo que se refiere a la disponibilidad e interés general. Por eso se plantea la pregunta de que si estos trabajos y conclusiones se transmitieron en el discurso cotidiano sobre la "nación mexicana".

Tal como sucedió frecuentemente durante esta época, los investigadores aquí presentados fueron al mismo tiempo personalidades directivas y desempeñaron sus respectivos cargos. Estos cargos influyeron en el canon de la historiografía, por ejemplo en la recepción y presentación de la historia indígena en los museos. Sin embargo, no quiero hablar aquí de las primeras exhibiciones que estaban accesibles sólo a una pequeña parte de la población. Como ejemplo para la divulgación de trabajos científicos en el discurso que concierne a toda la sociedad, elegí la presentación de soberanos aztecas en bustos y monumentos colocados en las avenidas de la Ciudad de México y en particular, en el Paseo de la Reforma. El Paseo de la Reforma es hasta hoy el bulevar más grande de la Ciudad de México. Une el parque de Chapultepec con la plaza rectangular de la Alameda, en el centro. Originalmente, el emperador Maximiliano había encargado la construcción de la avenida según diseños parisinos y la nombró en honor 
a su esposa, la emperatriz Carlotta, la Calzada de la Emperatriz. Después del ocaso de Maximiliano se perdió el interés en completar la avenida. Esto cambió en 1873, cuando el empresario de ferrocarril, Antonio Escandón, donó un monumento en honor a Cristóbal Colón que fue establecido en el Paseo. Este hecho atrajo a los indigenistas en el gobierno de Porfirio Díaz (1873-1910) a utilizar la avenida para crear un mito nacional.

Vicente Riva Palacios, el novelista histórico que bajo Díaz había ascendido a Ministro de Fomento (1876-1880), abrió un concurso para premiar al mejor monumento del joven y valiente soberano azteca Cuauhtemoc. Después de varias disputas políticas y el cese de Riva Palacio el monumento finalmente fue inaugurado en 1887. En el trabajo de Barbara Tenenbaum se presenta una amplia descripción de la ceremonia inaugural:

At 8 a.m. on the morning of August 21, 1887, civil and military leaders, the Ayuntamiento, workers' societies, students, and invited commissions representing various communities gathered at the second glorieta of the Paseo de la Reforma. Upon arrival of President Díaz, soldiers fired a 21-gun salute and military bands played the National Anthem. The licenciado Alfredo Chavero, author of the first volume of the liberal history which Riva Palacio edited, México a través de los siglos, gave his address. After the First Magistrate of the Supreme Court unveiled the monument and another 21-gun salute was fired, Francisco del Paso y Troncoso delivered an address in Nahuatl. Francisco Sosa, Eduardo del Valle, and Amalio José Cabrera each recited poems, Demetrio Mejía read a prose selections, and the bands played (Tenenbaum 1992: 375).

La elección del soberano azteca Cuauhtemoc se puede comprender bien ya que representa la resistencia joven y heroica contra los conquistadores españoles. Por lo tanto se convirtió, a causa de su ejecución por los españoles en 1525 , en una de sus víctimas inocentes y "puras" más marcadas, un símbolo y ejemplo para el México independiente emergente. Más tarde siguieron monumentos en honor al soberano azteca Motecuhzoma II y al primer presidente republicano Benito Juárez, con lo cual se cerró el círculo histórico del pasado y presente de una nación que se organizó en este momento. Los monumentos forman parte del Paseo hasta hoy en día.

En fin, ¿cuál podría ser el impacto de esas obras monumentales en la joven historia nacional de México? Una respuesta al respecto la brinda la investigación de la socióloga Natividad Gutiérrez. En los años 1990, ella encuestó a dos grupos de estudiantes acerca de sus 
ideales históricos. La mayoría de los estudiantes del grado básico mencionó a Benito Juárez y a Lázaro Cárdenas ${ }^{14}$ del período nacionalista de México. En cambio, el grupo de los estudiantes posgraduados prefirió a los dos héroes prehispánicos, Moctezuma y Cuauhtemoc (Gutiérrez 1999: 177). Claro que estas opiniones no son el resultado de solamente unos monumentos en el espacio público, sino remiten a los entrelazamientos entre discurso académico, retórica política $(\mathrm{y}-\mathrm{en}$ consecuencia- en la educación pública) y el pensamiento ciudadano.

\section{Bibliografía}

Acosta, José de ([1590] 1987): Historia Natural y Moral de las Indias. Madrid: Historia 16.

Alva Ixtlilxochitl, Fernando de (1975-1977): Obras históricas. 2 tomos. Trad. de Edmundo O’Gorman. México, D.F.: Universidad Nacional Autónoma de México.

Alvarado Tezozomoc, Hernando de ([1609] 1975a): Crónica mexicáyotl. Trad. de Adrián León. México, D.F.: Universidad Nacional Autónoma de México.

- (1975b): Crónica Mexicana. Ed. de Manuel Orozco y Berra. México, D.F.: Editorial Porrúa.

Anders, Ferdinand/Jansen, Maarten (1988): Schrift und Buch im Alten Mexiko. Graz: ADENA.

Arellano Hoffmann, Carmen/Schmidt, Peer (eds.) (1999): Die Bücher der Maya, Mixteken und Azteken. Die Schrift und ihre Funktion in vorspanischen und kolonialen Codices. Frankfurt am Main: Vervuert.

Chimalpahin Cuauhtlehuanitzin, Domingo Francisco de San Antón Muñon (1965): Relaciones originales de Chalco Amequamecan. Trad. de Silvia Rendón. México, D.F.: Fondo de Cultura Económica.

- (1997): Codex Chimalpahin: Society and Politics in Mexico Tenochtitlan, Tlatelolco, Texcoco, Culhuacan, and Other Nahua Altepetl in Central Mexico. The Nahuatl and Spanish Annals and Accounts Collected and Recorded by Don Domingo de San Antón Muñon Chimalpahin Cuauhtlehuanitzin. 2 tomos. Ed. de Arthur J. O. Anderson, Susan Schroeder y Wayne Ruwett. Norman: University of Oklahoma Press.

Clavijero, Francisco Javier (1780-81): Storia antica del Messico cavata da' Miglori storici Spagnuoli, e da' manoscritti, e dalle pitture antiche degl' Indiani: divisa en dieci libri, e corredata di carte geografiche, e di varie figure; e dissertazione

14 Mientras que Benito Juárez desde 1856 hasta 1872 formó las bases de un México moderno (con interrupción por el régimen de Maximiliano, 1862-1866), la presidencia de Lázaro Cárdenas (1933-1939) se ha incorporado a la historia de México a través de la repatriación de la explotación petrolera y de una extensa reforma territorial. 
sulla terra, suglo animali, e suglo abitatori del Messico. 4 tomos. Per Gregorio Biasini All' Insegna di Pallade. Con Lizenza de' Superiore. Cesena: Gregorio Biasini.

- (1968): Historia antigua de Mexico. Edición y prólogo de Mariano Cuevas. México, D.F.: Editorial Porrúa.

Clendinnen, Inga (1987): Ambivalent Conquests. Maya and Spaniard in Yucatan, 1517-1570. Cambridge: Cambridge University Press.

Cline, Howard F. (1973): "Selected Nineteenth-Century Mexican Writers on Ethnohistory". En: Handbook of Middle American Indians. Tomo 13: Guide to Ethnohistorical Sources. Austin: University of Texas Press, t.13, parte 2, pp. 370-427.

Codex Mendoza (1992). Ed. de Frances Frei Berdan y Patricia Rieff Anawalt. Berkeley: University of California Press.

Coe, Michael D. (1992): Breaking the Maya Code. London: Thames and Hudson.

Díaz, Gisele/Rodgers, Alan (eds.) (1993): The Codex Borgia. A Full-Color Restoration of the Ancient Mexican Manuscript. New York: Dover Publications.

Eggebrecht, Eva (2000): "Spurensuche - Zur Entdeckung der Maya durch die Wissenschaft”. En: Grube, Nikolai (ed.): Maya - Gottkönige im Regenwald. Köln: Könemann, pp. 397-411.

Gibson, Charles (1973): "Published Collections of Documents Relating to Middle American Ethnohistory”. En: Handbook of Middle American Indians. Tomo 13: Guide to Ethnohistorical Sources. Austin: University of Texas Press, t. 13, parte 2, pp. 3-41.

Glass, John B. (1975a): "A Survey of Native Middle American Pictorial Manuscripts". En: Handbook of Middle American Indians. Tomo 14: Guide to Ethnohistorical Sources. Austin: University of Texas Press, t. 14, parte 3, pp. 3-80.

- (1975b): "The Boturini Collection". En: Handbook of Middle American Indians. Tomo 14: Guide to Ethnohistorical Sources. Austin: University of Texas Press, t. 14, parte 3, pp. 473-486.

Gutiérrez, Natividad (1999): Nationalist Myths and Ethnic Identities. Indigenous Intellectuals and the Mexican State. Lincoln/London: University of Nebraska Press.

Humboldt, Alexander von (1810): Vue des Cordillères et monuments des peuples indigènes de l'Amérique. Paris: F. Schöll.

Keen, Benjamin ( $\left.{ }^{5} 1991\right)$ : Latin American Civilization. Boulder: Westview Press.

Kingsborough, Lord Edward King (1831-1848): Antiquities of Mexico. Comprising Facsimiles of Ancient Mexican Paintings and Hieroglyphics. 9 tomos. London: s.e.

Lacadena, Alfonso (1999): "Codices und ihre Funktion für die Religion in der Mayagesellschaft”. En: Arellano Hoffmann, Carmen/Schmid, Peer (eds.): Die Bücher der Maya, Mixteken und Azteken. Die Schrift und ihre Funktion in vorspanischen und kolonialen Codices. Frankfurt am Main: Vervuert, pp. 237-256.

Landa, Diego de ([1570] 1995): Relación de las Cosas de Yucatán. Mérida: San Fernando. 
López Cogolludo, Diego ([1656] 1971): Los Tres Siglos de la Dominación Española en Yucatan o sea Historia de esta Provincia. Ed. de Edmundo O'Gorman. Graz: Akademische Druck- und Verlagsanstalt.

López de Gómara, Francisco ([1552] 1965): Historia General de las Indias. 2 tomos. Barcelona: Editorial Iberia.

Love, Bruce (1994): The Paris Codex. Handbook for a Maya Priest. Austin: University of Texas Press.

Monumenta Germaniae Historica (<www.mgh.de/dmgh/>; 05.07.2010).

Motolinia, Fray Toribio de Benavente ([1569] $\left.{ }^{6} 1995\right)$ : Historia de los indios de la Nueva España. Relación de los ritos antiguos, idolatrías y sacrificios de los indios de la Nueva España, y de la maravillosa conversión que Dios en ellos ha obrado. Ed. de Edmundo O’Gorman. México, D.F.: Editorial Porrúa.

Peoples, James/Bailey, Garick ( $\left.{ }^{8} 2006\right)$ : Humanity. An Introduction to Cultural Anthropology. Belmont: Wadsworth.

Prescott, William Hickling (1836): History of the Conquest of Mexico. 3 tomos. London: R. Bentley.

- (1844): "Notas y esclarecimiento a la Historia de la Conquista de México del Sr. William Prescott". En: Prescott, William Hickling: Historia de la Conquista de México ... 3 vols. Traducción de Joaquín Navarro. México: Ignacio Cumplido.

Ramírez, José F. (1845): "Notas y esclarecimientos a la Historia de la conquista de México del señor W. Prescott". En: Prescott, William Hickling: Historia de la conquista ... 3 vols. Traducción de Joaquín Navarro. Vol. 2. México: Ignacio Cumplido.

- (1847): Proceso de residencia contra Pedro de Alvarado, ilustrado con estampas sacadas de los antiguos códices mexicanos, y notas y noticias biográficas, criticas, y arqueológicas. Paleografiado del manuscrito original el Lic. Ignacio L. Rayón. México, D.F.

- (1863): El bautismo de Motecuhzoma II, noveno rey de México. México, D.F.: Boletín de la Sociedad Mexicana de Geografía y Estadística, tomo 10, pp. 357381.

- (2001): Obras históricas. Época prehispánica (Nueva Biblioteca Mexicana, 136). Ed. de Ernesto de la Torre Villar. México, D.F.: Instituto de Investigaciones Históricas, Universidad Nacional Autónoma de México.

Ray, John (2007): The Rosetta Stone and the Rebirth of Ancient Egypt. London: Profile Books.

Río, Antonio del ([1787] 1822): Description of the Ruins of an Ancient City Discovered Near Palenque, in the Kingdom of Guatemala, in Spanish America. Traducción del Español. London: Berthoud and Suttaby, Evance and Fox.

Robertson, Donald (1994): Mexican Manuscript Paintings of the Early Colonial Period. The Metropolitan Schools. Norman/London: University of Oklahoma Press.

Ronan, Charles E. S. J. (1973): "Francisco Javier Clavigero, 1731-1787". En: Handbook of Middle American Indians. Tomo 13: Guide to Ethnohistorical Sources. Austin: University of Texas Press, t. 13, parte 2, pp. 276-297. 
Sahagún, Bernardino de ([1569] 1989): Historia General de las Cosas de Nueva España. México, D.F.: Editorial Porrúa.

- ([1585] 1970): Codex Florentinus/Florentine Codex. General History of the Things of New Spain. 13 tomos. Traducido del náhuatl al inglés por Arthur J. O. Anderson y Charles E. Dibble. Santa Fe: The School of American Research/ University of Utah.

Sánchez de Aguilar, Pedro ([1639] 1987): "Informe contra Idolorum Cultores del Obispado de Yucatan". En: El Alma Encantada. Anales del Museo Nacional de México. Presentado por Fernando Benítez. México, D.F.: Instituto Nacional Indigenista, pp. 15-122.

Seler, Eduard (1963): Comentarios al Códice Borgia. Traducción de Mariana Frenk. 3 tomos. México, D.F.: Fondo de Cultura Económica.

Sisson, Edard B. (1983): "Recent work on the Borgia Group Codices". En: Current Anthropology, 24, 5, pp. 653-656.

Stagl, Justin (2006): "Die Entwicklung der Ethnologie". En: Fischer, Hans/Beer, Bettina (eds.): Ethnologie - Einführung und Überblick. Berlin: Reimer, pp. 3352.

Tedlock, Dennis ( $\left.{ }^{2} 1996\right)$ : Popol Vuh. The Definitive Edition of the Mayan Book of the Dawn of Life and the Glories of Gods and Kings. New York: Simon \& Schuster.

Tenenbaum, Barbara (1992): "Murals in Stone. The Paseo de la Reforma and Porfirian Mexico, 1873-1910". En: La ciudad y el campo en la historia de México. Memoria de la VII Reunión de Historiadores Mexicanos y Norteamericanos, Oaxaca, 1985. México, D.F.: Universidad Nacional Autónoma de México. T. I, pp. 369-379.

Thompson, Eric Sidney (1972): Un comentario al Códice de Dresde. Libro de jeroglifos mayas. México, D.F.: Fondo de Cultura Económica.

Torre Villar, Ernesto de la (2001): "Ramírez historiador". En: Ramírez, José Fernando: Obras históricas. Época prehispánica (Nueva Biblioteca Mexicana, 136). Ed. de Ernesto de la Torre Villar. México, D.F.: Instituto de Investigaciones Históricas/Universidad Nacional Autónoma de México.

Vail, Gabrielle/Aveni, Anthony (eds.) (2004): The Madrid Codex. New Approaches to Understanding an Ancient Maya Manuscript. Boulder: University of Colorado Press. 